\title{
Polypharmacy Is Associated with Frailty, Nutritional Risk and Chronic Disease in Chilean Older Adults: Remarks from PIEl-ES Study
}

This article was published in the following Dove Press journal: Clinical Interventions in Aging

\author{
Diego Arauna $\mathbb{( D}^{1, *}$ \\ Alvaro Cerda ${ }^{2,3, *}$ \\ José Francisco García- \\ García $^{4}$ \\ Sergio Wehinger' \\ Felipe Castro ${ }^{5}$ \\ Diego Méndez $\mathbb{D}^{\prime}$ \\ Marcelo Alarcón' \\ Eduardo Fuentes ${ }^{1,2}$ \\ Iván Palomo ${ }^{1,2}$ \\ 'Thrombosis Research Center, \\ Department of Clinical Biochemistry and \\ Immunohematology, Faculty of Health \\ Sciences, Interdisciplinary Excellence \\ Research Program on Healthy Aging \\ (PIEI-ES), Interdisciplinary Center on \\ Aging, Universidad de Talca, Talca, Chile; \\ ${ }^{2}$ Thematic Task Force on Healthy Aging, \\ CUECH Research Network, Viña Del \\ Mar, Chile; ${ }^{3}$ Center of Excellence in \\ Translational Medicine, CEMT-BIOREN, \\ Department of Basic Sciences, \\ Universidad de la Frontera, Temuco, \\ Chile; ${ }^{4}$ Department of Geriatric \\ Medicine, Complejo Hospitalario de \\ Toledo, Toledo, Spain; ${ }^{5}$ School of \\ Medicine, Universidad de Talca, Talca, \\ Chile
}

*These authors contributed equally to this work

\begin{abstract}
Aim: To analyze the relationship between polypharmacy and variables as frailty and other chronic comorbidities in Chilean older adults.

Design: Cross-sectional study.

Participants: One thousand two hundred and five older adults aged 65 and older.

Methods: The presence or absence of frailty syndrome was determined according to Fried criteria. Data collection was made through questionnaires conducted by an interview.

Results: The prevalence of polypharmacy was $37.59 \%$. The prevalence of hyperpolypharmacy was $2 \%$. Increased prevalence of frailty was demonstrated regarding the progression of the state of polypharmacy. When analyzing the contribution of frailty respect polypharmacy condition, frail state, nutritional risk and obesity are founded as a factor associated with polypharmacy. Regarding chronic disease, hypertension (OR: 8.039, p<0.0001), type 2 diabetes (OR: 4.001, $\mathrm{p}<0.0001$ ) and respiratory diseases (OR: 2.930, $\mathrm{p}<0.0001$ ) were associated to polypharmacy. It was found a strong and significant positive correlation between polypharmacy prevalence and frailty score (polypharmacy condition, Spearman R: 0.89, $\mathrm{p}=0.033$; hyperpolypharmacy condition, Spearman $\mathrm{R}: 0.94, \mathrm{p}=0.016)$. When analyzing the contribution of the polypharmacy to the presence of frailty, polypharmacy condition (OR: $1.510, \mathrm{p}<0.05$ ), cognitive impairment (OR: 3.887, $\mathrm{p}<0.001$ ), obesity (OR: $1.560, \mathrm{p}<0.01)$ and nutritional risk (OR: 2.590, $\mathrm{p}<0.001)$ are associated to frailty.

Conclusion: Frailty and chronic conditions as nutritional risk, obesity, hypertension, type 2 diabetes and respiratory disease are an important risk factor for the development of polypharmacy in Chilean older adults. Likewise, polypharmacy condition was observed to be a risk factor for frailty, demonstrating the bidirectional relationship between both conditions. Frailty syndrome evaluation in Chilean older adults could be an important alternative for polypharmacy prevention.
\end{abstract}

Keywords: frailty, polypharmacy, chronic disease, older adults, aging

\section{Highlights/Plain Language Summary}

Dr Arauna and his team observed in this Chilean cohort, a prevalence of polypharmacy and hyperpolypharmacy of $37.6 \%$ and $2 \%$, respectively. The correlation, in older adults, between Frailty score and conditions related to the number of drugs consumed, was stronger in polypharmacy and hyperpolypharmacy ones. Regarding the presence and absence of polypharmacy conditions among older adults, there were observed no differences in age, residential area or years of education. Frail state and high-prevalence of chronic conditions in older people, as could be the nutritional risk, obesity, hypertension, diabetes, and respiratory diseases, were significant
Correspondence: Eduardo Fuentes; Iván Palomo

Email edfuentes@utalca.cl; ipalomo@utalca.cl 
risk factors for polypharmacy. Frailty status evaluation in older adults could be an important aspect to consider the risk of developing polypharmacy condition.

\section{Introduction}

Given the global demographic dynamics, there is an exacerbated increase in aging and the prevalence of older adults, projecting a world population of 9.3 billion people by 2050 (22\% of all population), showing a difference of $11.2 \%$ compared with the year 2011. ${ }^{1}$ The Medical Expenditure Panel Survey in 2006 states that $90.7 \%$ of +65 age adults in the USA suffer from at least one chronic disease, ${ }^{2}$ a condition which supposes an increase in using drugs in this population and relates with the fact that the medicament consumes increase regarding aging. ${ }^{3}$ So, it is important to remark that these diseases increase health expenditure, due to a higher demand of drugs leading to increased expenditures in hospitalization. ${ }^{4}$

The Chilean reality does not differ from the rest of the world, presenting an increase in the prevalence of older adults, and chronic diseases such as hypertension, type 2 diabetes (T2D) and metabolic syndrome, as reported by the National Health Survey (ENS) of the year 2016-2017. 5 An important concern of an increasing elderly population, and its related higher prevalence of chronic diseases, is the necessity of the daily use of drugs, often generating a condition called "polypharmacy", which refers to the use of multiple medications, being different ways to define it, as could be, incorporating therapy's duration, appropriate and inappropriate drugs regarding polypharmacy tools as Beers criteria and the Medication Appropriateness Index (MAI), but concerning older adults, the most used way is pure numerical, being the cut-off point, the consumption of 5 or more drugs daily. ${ }^{6,7}$ In a German cohort of 3058 older adults (ESTHER cohort) an association was detected between the presence of polypharmacy with a greater risk of frailty. ${ }^{7,8}$ Frailty has been defined as a clinical condition characterized by an increase in patient vulnerability, given a detriment (associated with age) in the reserve and function of multiple physiological systems. $^{9-11}$ It is crucial to emphasize the importance of the relationship between polypharmacy and frailty because there is sufficient evidence that supports a joint increase in the incidence of geriatric problems such as depression, cognitive disability, hospitalizations, and death. ${ }^{12-14}$ This increase in comorbidities and hospitalizations could mean an unsustainable increase in expenses for this age group in any public health system. ${ }^{15-17}$ Further, frailty would be a predictor of worsening mobility or difficulty in performing day-to-day activities (ADL disabilities), deteriorating the quality of life in older adults. ${ }^{11}$

Recently, Palomo et al reported a prevalence of approximately $26 \%$ in the presence of frailty-defined by modified Fried's criteria in elderly Chilean adults, which would be related to low education level, bad nutrition and mild cognitive impairment. ${ }^{18}$ This number could increase, regarding the exponential augment of older than 65 years population, being so, necessary to identify risk factors to focus preventive strategies. ${ }^{5,19}$ There is a lack of data regarding the prevalence of polypharmacy in elderly adults in Chile. A study performed in the Universidad de Chile states that $53 \%$ of its sample suffer from polypharmacy. ${ }^{20}$ SABE study stated a much fewer percentage in Brazilian older (36\%). ${ }^{21}$

Notwithstanding the novelty of the idea regarding the relationship between polypharmacy and frailty, there is a lot of conclusive evidence that support it, as can be seen in Palmer et al. ${ }^{22}$ On the other hand, in Chilean reality, there is a lack of information regarding this topic. This study aims to analyze the relationship between polypharmacy and variables as frailty and other chronic comorbidities in Chilean older adults.

\section{Materials and Methods}

\section{Participants}

The participants of this research belong to the sample described by the Interdisciplinary Excellence Research Program on Healthy Aging (PIEI-ES, University of Talca) in a study about frailty in the Chilean elderly. ${ }^{18}$ This cohort belonged to a cross-sectional study conducted between September 2016 and October 2017 in health care centers in the Region del Maule in central Chile. The sample of 1205 community-dwelling older adults, aged 65 and older, were randomly selected from four urban provincial capitals and two rural communes per capital. Being the proportions regarding residence area determined by the relative amount of the adult population over 65 years of age, based on data from the Casen 2013 survey. Exclusion criteria rely on walking impairment and the refusal of older adults to participate. Finally, the sample size calculation was made considering a significance level of 0.05 (two-sided), $80 \%$ power, loss to follow-up rate of $20 \%$ and a prevalence of frailty syndrome in Chile of $\approx 22 \%$ (32). The Scientific Ethics Committee from the University of Talca approved the study. After being 
recruited, all subjects underwent a standardized assessment including interviews and physical examinations.

\section{Diagnosis of Frailty}

The diagnosis of frailty was made as described by Palomo et al, according to Fried criteria. ${ }^{18}$ This frailty criterion was based on the presence or absence of the following five measurable components: slowness, weakness, weight loss, exhaustion, and low physical activity. Briefly, slowness was defined according to a cut-off $(<0.8 \mathrm{~m} / \mathrm{s})$ on three-meter walking at a usual pace, adjusted for sex and height according to the standards of the Short Physical Performance Battery. ${ }^{23}$ To assess weakness, strength was measured with an Electronic Handgrip Dynamometer (Camry, City Industry, USA), according to a sex-specific cut-off (male $<27 \mathrm{~kg}$, female $<15 \mathrm{~kg}$ ). ${ }^{24}$ Unintentional weight loss was defined as a self-reported loss of at least $5 \mathrm{~kg}$ in the previous 6 months. ${ }^{25}$ Exhaustion was classified when participants provided a positive answer to any of the following two questions from the Center for Epidemiological Studies Depression Scale: "I felt that anything I did was a big effort" and "I felt that I could not keep on doing things at least 3 to 4 days a week". ${ }^{26}$ Finally, low physical activity was defined by difficulty walking using two questions "Do you have difficulty walking a block?" or "Do you have difficulty climbing several flights of stairs without resting?". ${ }^{25,27}$ Subjects were classified as frail if they met three or more of these components, as pre-frail if subjects met one or two components, and non-frail or robust if none of the components were present. ${ }^{26}$

\section{Data Collection and Definition of Polypharmacy}

Data collection of comorbidity was done from medical diagnoses and the information given by the subject. Furthermore, there were employed questionnaires, which included socio-demographic variables like age, gender, educational level, and residence area; cognitive impairment, measured by Mini-Mental State Examination with a cutoff point $\leq 13$ points, consequently with Chilean reality, and nutrition screening, measured by Mini-Nutritional Assessment Short Form (MNA). Scores below 12 points in the MNA were classified as "nutritional risk". The functional risk was assessed using a score validated in Chile, whose name is Functional Assessment of Older Adults (EFAM). Finally, anthropometric variables (weight, height, Body Mass Index and waist circumference) were also measured. Everything as described by Palomo et al. ${ }^{18}$
The data about polypharmacy were conducted by an interview. A pre-trained interviewer asks the subject "How many different drugs do you use prescribed by a doctor?". The interviewer clarifies to the older adult that the question refers to the total number of different drugs and not to the "number of pills consumed per day." If the older adult unknown your pharmacological treatment, a relative or caregiver responsible for the elderly person was contacted by telephone. The interviewer recorded the response of the older adult or caregiver in charge. Also, a pre-trained interviewer asks the subject "From the following list of drugs, which ones do you consume?" The interviewer marks the response according to the list of drugs described in the list (Supplementary Material). We categorized the total amount of drugs consumed into three categories: non-polypharmacy (0-4 drugs), polypharmacy (5-9 drugs), and hyperpolypharmacy (10 or more drugs) as described by Gnjidic et al. ${ }^{7}$ Also, by a questionnaire, we obtained the sociodemographic information about age, gender, educational years, residential area, body mass index (BMI), and comorbidities. The prevalence of mild cognitive impairment was tested by Mini-Mental State Examination (MMSE) developed by Folstein and collaborators in 1975, but with modifications according to the Chilean reality. The clinical condition of nutritional risk was determined by the Mini-Nutritional Assessment (MNA). Scores below 12 points in the MNA were classified as "nutritional risk". Obesity was defined according to WHO criteria $\left(\mathrm{BMI}>30 \mathrm{Kg} / \mathrm{m}^{2}\right)$. Chronic diseases such as hypertension, $\mathrm{T} 2 \mathrm{D}$, and respiratory disease were obtained through an interview and self-report.

\section{Statistical Analysis}

Data obtained were analyzed using the SPSS Statistics software version 17 (SPSS Inc., Chicago, Ill., USA). Continuous variables were expressed as mean $\pm \mathrm{SD}$. Categorical variables were expressed as percentages and a $95 \%$ confidence interval (CI). In the analysis of differences between groups, the Chi-Squared test with Yate's correction was used to assess differences in proportions and one-way ANOVA with Dunn's posthoc test for comparisons of means of three or more groups. Correlation analyses were performed by estimating the Spearman correlation coefficient. Logistic regression models were performed to evaluate the contribution of studied variables on risk frailty and polypharmacy, unadjusted and adjusted. Besides, the presence of 
multicollinearity was evaluated in a regression analysis. P-values lower than 0.05 were considered statistically significant.

\section{Results}

The prevalence of polypharmacy conditions in our cohort was $37.6 \%$, while the prevalence of older adults who did not have polypharmacy was $60.4 \%$. The prevalence of hyperpolypharmacy was $2 \%$. Whereas the mean number of drugs consumed by patients in no polypharmacy, polypharmacy and hyperpolypharmacy condition was $2.54 \pm 1.24$ drugs per day, $6.11 \pm 1.18$ drugs per day and $11.0 \pm 1.02$ drugs per day, respectively, the overall mean number of drugs consumed was $4.05 \pm 2.32$ drugs per day. The characteristics of the subjects according to the polypharmacy status are shown in Table 1. When seeing the statistical analyses among the three groups (Nonpolypharmacy, Polypharmacy, and Hyperpolypharmacy), statistically significant differences were found in the percentage of men and women $(p=0.0002)$, getting a higher percentage of women as the progress of the state of polypharmacy. In addition, we found significant differences in BMI $(p<0.0001)$ and Mild cognitive impairment $(\mathrm{p}=0.0025)$, both parameters with increasing values through the progress of the polypharmacy status. When analyzing the Comorbidities (Hypertension; Diabetes; Respiratory disease between the three groups), we obtained significant differences ( $p$ $<0.0001$ ), showing a higher consumption of drugs with a higher prevalence of Comorbidities in the subjects of this study. When testing Frailty status (Non-frail; Pre-frail; Frail) there are significant differences $(p<0.0001)$, resulting in an increase in frailty, as the polypharmacy status progress.

Table 2 shows the results of not-adjusted logistic linear regression evaluating the contribution of frailty clinical variables to the risk of polypharmacy. Polypharmacy status was associated with conditions like frail status, cognitive impairment, nutritional risk, and chronic diseases.

When analyzing the adjusted logistic regression (considering all covariates, sex, and age) (Table 2), variables as frailty state, obesity, hypertension and T2D demonstrated to increase the risk of polypharmacy status. Collinearity analyses are also shown in Table 2. We noted that none of the variables have positive indicators of the presence of collinearity (tolerance $>0.10$ and VIF $<4$ ).

Table 3 shows the results of a not-adjusted logistic linear regression between polypharmacy condition, frailty syndrome and clinical variables, considering frailty state as a dependent variable. Regarding this, the risk of suffering frailty state was increased by conditions like polypharmacy and chronic diseases. When analyzing the adjusted logistic regression (considering all covariates, sex, and age) (Table 3), the following variables remained significant as risk factors for frailty state: Polypharmacy condition, cognitive impairment, obesity, and nutritional risk. None of the variables have positive indicators of the presence of collinearity (tolerance $>0.10$ and VIF $<4$; Table 3).

Figure 1 shows the correlation between the frailty score and the prevalence of polypharmacy status. Respect to polypharmacy status, there is a significant positive correlation ( $\mathrm{p}=0.03$, Spearman $\mathrm{R}=0.89$ ), where we observed an increase in the prevalence of this status according to the increase of frailty score. Similarly, a marked correlation is detected when analyzing the state of hyperpolypharmacy $(\mathrm{p}=0.02$, Spearman $\mathrm{R}=0.94)$.

Confirming what was observed above, Figure 2 shows a higher frailty score in the states of polypharmacy ( $p$ $<0.0001$ ) and hyperpolypharmacy ( $<<0.001)$, compared to older adults who do not have this state. However, this difference is not observed when we compare both groups that have polypharmacy. Figure 3 shows the average number of daily medications by the state of frailty. There are significant differences between the frail and non-frail groups $(\mathrm{p}<0.0001)$, which shows a greater consumption of daily medications in the frail older adults of this study.

\section{Discussion}

The purpose of this study was to establish whether there is a relationship between frailty syndrome and polypharmacy conditions in older adults; being this study based on the information collected by the PIEI-ES on a group of participants of 1205 Chilean older adults. As was previously stated, the overall prevalence of polypharmacy found in our cohort was $39.59 \%$, a value that compared with the South American geriatric population (65 years or more), could be considered slightly high. For example, in Brazil, an approximate prevalence of $30.9 \%$ has been reported, while in Colombia it has seen an approximate prevalence of $27 \%{ }^{28,29}$

The collection of data about polypharmacy, by interview, as well as the design of this study, which was, crosssectional, are limitations in this study. However, there are some features which strength the relevance of its results, for instance, the sample's size (1205 older adults), being the second biggest cohort in Chile, related to this topic; incorporation of adults whose residence area is rural one, being the first study by this time in Chile, and the complete previous characterization of the frailty syndrome in this cohort. 
Table I Characteristics of Subjects According to Polypharmacy State

\begin{tabular}{|c|c|c|c|c|c|}
\hline Characteristics & Total Sample & $\begin{array}{l}\text { Non-Polypharmacy } \\
\text { (0-4 Drugs) }\end{array}$ & $\begin{array}{l}\text { Polypharmacy } \\
\text { (5-9 Drugs) }\end{array}$ & Hyperpolypharmacy (10 or More Drugs) & p-value \\
\hline Sample size (N, \%) & $1205(100.0)$ & $728(60.4)$ & $453(37.6)$ & $24(2.0)$ & - \\
\hline Age (mean, SD) & $73.1 \pm 5.9$ & $73.4 \pm 6$ & $73.3 \pm 5.7$ & $73.4 \pm 5.4$ & 0.8278 \\
\hline Gender (\%) & & & & & 0.0002 \\
\hline Female & $68.0(65.0-70.4)$ & $63.3(59.8-66.8)$ & $72.9(69.7-77.8)$ & $83.3(64.2-93.3)$ & \\
\hline Male & $32.0(29.7-35.0)$ & $36.7(33.3-40.2)$ & $27.1(22.2-30.3)$ & $16.7(6.7-35.9)$ & \\
\hline Residential area (\%) & & & & & 0.0828 \\
\hline Urban & $79.0(76.5-82.1)$ & $75.4(72.2-78.4)$ & $80.13(76.2-83.6)$ & $87.50(68.9-95.7)$ & \\
\hline Rural & $21.0(17.9-23.4)$ & $24.6(21.6-27.8)$ & $19.9(16.5-23.8)$ & $12.50(4.3-31.0)$ & \\
\hline Education years (mean, SD) & $7.2 \pm 4.2$ & $7.2 \pm 4.4$ & $7.2 \pm 4.4$ & $7.3 \pm 4.3$ & 0.9907 \\
\hline BMI (mean, SD) & $29 \pm 5.1$ & $28 \pm 50$ & $30 \pm 5,10$ & $31 \pm 5,40$ & $<0.0001$ \\
\hline Mild cognitive impairment & $19.0(16.8-22.4)$ & $16.0(13.5-18.9)$ & $22.9(19,3-27,1)$ & $33.3(17.9-53.3)$ & 0.0025 \\
\hline Comorbidities (\%) & & & & & $<0.0001$ \\
\hline Hypertension & 73.1 & $60.0(56.4-63.5)$ & $92.9(90.2-94.9)$ & 95.8 (79.8-99.8) & \\
\hline Diabetes & 35.4 & $22.1(19.3-25.3)$ & $54.5(49.9-59.1)$ & $75.0(55.1-88.0)$ & \\
\hline Respiratory disease & 10.9 & $6.59(5.0-8.6)$ & $16.56(13.4-16.6)$ & $37.50(21.2-37.5)$ & \\
\hline Frailty status (\%) & & & & & $<0.0001$ \\
\hline Non-frail & 36.5 & $40.5(37.0-44.1)$ & $30.9(26.8-35.3)$ & $20.8(9.2-40.5)$ & \\
\hline Pre-frail & 38.9 & $40.8(37.3-44.4)$ & $36.2(31.9-40.7)$ & $33.3(17.9-53.3)$ & \\
\hline Frail & 24.6 & $18.7(\mid 6.0-21.7)$ & $32.9(28.7-37.3)$ & $45.8(27.9-64.9)$ & \\
\hline
\end{tabular}

Notes: Chi-Squared test with Yate's correction was used to assess differences in proportions. ANOVA was used to assess differences in means. The bold text indicates a statistical significant difference between groups.

Abbreviation: BMI, body mass index.

Concerning demographical features of the studied population, gender distribution observed in the cohort reveal a clear higher frequency of female sex, which trend could be associated or explained because, in Chile, women assist more frequently into primary health services, as can seem in 2016-2017 ENS. It is important to tell that this is not isolated and can be observed similarly in another study like one deployed in France, which showed a prevalence in women of $59.4 \% .{ }^{14}$

Regarding the residence area, there was a significant difference between both rural and urban, being a clear trend to the urban one. The cohort's residential area characteristics could explain this demographical feature as can be seen in the 2017 CENSUS and the Casen 2015 survey. Another possible explanation would be the existence of influence in the accessibility to health services in drugs prescription, augmenting so the risk of polypharmacy. To clarify this trend, there would be necessary to perform more studies, which involves this feature.

There was a significant difference in other participant's characteristics that are also important to analyze, like BMI which trend to be associated with overweight in all the groups, or different comorbidities, like hypertension and diabetes, because it correlated with the Chilean reality, ${ }^{5}$ and because whenever these health issues cannot be solved with changes in lifestyle, it would be necessary to take medication, and so increasing the risk to fall into the polypharmacy condition.

When comparing the Polypharmacy group with the non-Polypharmacy group in a non-adjusted linear regression, there were found some risk factors linked to polypharmacy status, like Cognitive impairment, Depression, Hypertension, Diabetes, Respiratory disease, Obesity, nutritional risk, and Frailty. Regarding cognitive impairment, it is stated in the scientific literature that there is a relationship between this variable with the prescription of drugs, like anticholinergic drugs in the elderly population. ${ }^{30}$ This becomes relevant when considering its clinical implication in the treatment of some diseases, like atrioventricular block, a condition whose incidence trend to increase with aging; and could be considered more important because of its risky relationship with frailty. ${ }^{31}$ Regarding comorbidities like Hypertension, Diabetes, Respiratory disease, obesity, and depression, this statistical analysis allows relating significantly high prevalence Chilean diseases ${ }^{5}$ with polypharmacy condition, and with 
Table 2 Contribution of Frailty Syndrome and Clinical Variables to Polypharmacy Condition

\begin{tabular}{|c|c|c|c|}
\hline \multicolumn{4}{|l|}{ Logistic Regressions } \\
\hline \multicolumn{4}{|c|}{ Not-Adjusted Logistic Regression } \\
\hline \multirow{2}{*}{\multicolumn{2}{|c|}{ Variables }} & \multicolumn{2}{|c|}{ Polypharmacy vs Non-Polypharmacy } \\
\hline & & OR $(95 \% \mathrm{Cl})$ & p-value \\
\hline Frail & & $2.394(1.768-3.240)$ & $<0.0001$ \\
\hline Pre-frail & & $1.178(0.896-1.549)$ & 0.240 \\
\hline Cognitive impairment & & $1.608(1.203-2.150)$ & $<0.001$ \\
\hline Obesity & & $1.812(1.429-2.296)$ & $<0.0001$ \\
\hline Nutritional risk & & $1.767(1.362-2.293)$ & $<0.0001$ \\
\hline Current smoker & & $0.654(0.406-1.053)$ & 0.080 \\
\hline Depression & & $3.470(2.452-4.911)$ & $<0.0001$ \\
\hline Hypertension & & $8.959(6.106-13.147)$ & $<0.0001$ \\
\hline Type 2 diabetes & & $4.402(3.423-5.66 \mathrm{I})$ & $<0.0001$ \\
\hline Respiratory disease & & $3.028(2.080-4.409)$ & $<0.0001$ \\
\hline \multicolumn{4}{|c|}{ Multiple Adjusted Logistic Regression } \\
\hline Co-Variables & Tolerance & VIF & OR (IC 95\%) \\
\hline Frail & 0.734 & 1.362 & $1.533(1.074-2.190) *$ \\
\hline Cognitive impairment & 0.859 & 1.164 & I.I44 (0.795-I.648) \\
\hline Nutritional risk & 0.873 & 1.145 & $1.584(1.085-2.079)^{* *}$ \\
\hline Obesity & 0.932 & 1.073 & $1.476(1.114-1.956)^{* *}$ \\
\hline Hypertension & 0.931 & 1.074 & $8.039(5.332-12.120) * * * * *$ \\
\hline $\mathrm{T} 2 \mathrm{D}$ & 0.942 & 1.062 & $4.001(3.015-5.309) * * * *$ \\
\hline Respiratory disease & 0.975 & 1.026 & $2.930(1.868-4.595)^{* * * *}$ \\
\hline
\end{tabular}

Notes: The regression model was performed using polypharmacy (including higher polypharmacy status) as the dependent variable and clinical conditions as independent variables. Variables were selected according to its significance in the univariate model and the model was also adjusted for sex and age. ${ }^{*} \mathrm{p}<0.05$, $* * p<0.0 \mathrm{I},{ }^{*} * * * \mathrm{p}<0.000 \mathrm{I}$. The bold text indicates a statistical significant difference between groups.

Abbreviations: OR, odds ratio; $\mathrm{Cl}$, confidence interval; VIF, variance inflation factor; T2D, type 2 diabetes.

its treatment that should be medication. About frail status, this association has been stated in other studies like the one performed by Wang et al or by Saum et al and could be originated because of the inherent characteristics of this status or because of its relationship with comorbidities, which need to be treated with medicaments in elderly patients. ${ }^{8,32}$

Once a logistic regression analysis between polypharmacy and other variables, adjusted for potential confounding variables such as age and gender, was performed, there were found different risk factors to fall into this condition like hypertension, diabetes, and respiratory disease, as could seem in the prior analysis. Regarding the first couple of variables, this relationship was also present in other studies, like the one performed by Aubert et al, who also found an indeterminate relationship regarding respiratory disease. ${ }^{33}$ Another risk factors - whose behavior remained the same after the adjustment - were a nutritional risk, obesity, and Frailty, confirming so, that regardless of sex or age, these variables exert an increase in the risk of suffering polypharmacy. On the topic of frailty, which variable deploys the aim of this study, it is important to note its behavior coincides with other studies. ${ }^{14}$

When we analyze the contribution of the polypharmacy status to the presence of frailty, an increased risk is observed in older adults with the polypharmacy condition (OR: 1.510 , p-value $<0.05$ ). Also, the polypharmacy status has been associated with an increase of mortality, incident disability, hospitalization, and emergency department visits in frail and pre-frail older adults, however, these effects are not observed in healthy older adults (non-frail). ${ }^{13}$ Despite this context, a reduction of polypharmacy condition could be a cautious strategy to prevent and manage frailty. ${ }^{34}$

It is important to remark the relevance of the use of Fried's frailty criteria or score because it is the most used criterion in clinical practice to standardize this geriatric condition. Between both states, non-polypharmacy and polypharmacy, and the frailty score, there was a significant 
Table 3 Contribution of Polypharmacy and Clinical Variables to Frailty Syndrome Condition

\begin{tabular}{|c|c|c|c|}
\hline \multicolumn{4}{|l|}{ Logistic Regressions } \\
\hline \multicolumn{4}{|l|}{ Not-Adjusted Logistic Regression } \\
\hline \multirow{2}{*}{\multicolumn{2}{|c|}{ Variables }} & \multicolumn{2}{|l|}{ Frail vs Non-Frail } \\
\hline & & OR (95\% Cl) & p-value \\
\hline Polypharmacy condition (include hyperpolypharmacy) & & $2.197(1.684-2.867)$ & $<0.0001$ \\
\hline Cognitive impairment & & $7.937(5.221-12.094)$ & $<0.0001$ \\
\hline Obesity & & $1.485(1.139-1.937)$ & 0.004 \\
\hline Nutritional risk & & $3.882(2.678-5.595)$ & $<0.0001$ \\
\hline Current smoker & & $1.008(0.605-1.68 I)$ & 0.975 \\
\hline Depression & & $2.555(1.81 \mathrm{I}-3.606)$ & $<0.0001$ \\
\hline Hypertension & & $1.698(1.232-2.339)$ & 0.001 \\
\hline Type 2 diabetes & & $1.477(1.128-1.932)$ & 0.004 \\
\hline Respiratory disease & & $1.901(1.297-2.785)$ & 0.001 \\
\hline \multicolumn{4}{|l|}{ Multiple Adjusted Logistic Regression } \\
\hline Co-Variables & Tolerance & VIF & OR (IC 95\%) \\
\hline Polypharmacy condition (include hyperpolypharmacy) & 0.726 & 1.378 & $1.510(1.081-2.108)^{*}$ \\
\hline Cognitive impairment & 0.940 & 1.064 & $3.887(2.8 \mid 0-5.376)^{* * *}$ \\
\hline Obesity & 0.959 & 1.043 & $1.560(1.160-2.099)^{* *}$ \\
\hline Nutritional risk & 0.789 & 1.267 & $2.590(1.856-3.614)^{* * * *}$ \\
\hline Depression & 0.787 & 1.270 & $1.189(0.780-1.813)$ \\
\hline Hypertension & 0.850 & 1.177 & $1.239(0.854-1.797)$ \\
\hline Type 2 diabetes & 0.860 & 1.163 & I.I $95(0.872-1.638)$ \\
\hline
\end{tabular}

Notes: The bold text indicates a statistical significant difference between groups. The regression model was performed using frailty syndrome (frail vs non-frail as reference) as a dependent variable and clinical conditions as independent variables. Variables were selected according to their significance in the univariate model and the model was also adjusted for sex and age. ${ }^{*} p<0.05,{ }^{* *} p<0.01$, $* * * p<0.001$.

Abbreviations: $\mathrm{OR}$, odds ratio; $\mathrm{Cl}$, confidence interval; VIF, variance inflation factor.

correlation, so where the lower the frailty score is, the prevalence of non-polypharmacy increases and the one of polypharmacy, decreases. It makes sense considering the results priory analyzed. The hyperpolypharmacy status was not correlated with the frailty score, could be explained by the fact hyperpolypharmacy condition involved only 24 participants, making necessary to perform other studies with a bigger amount of persons.

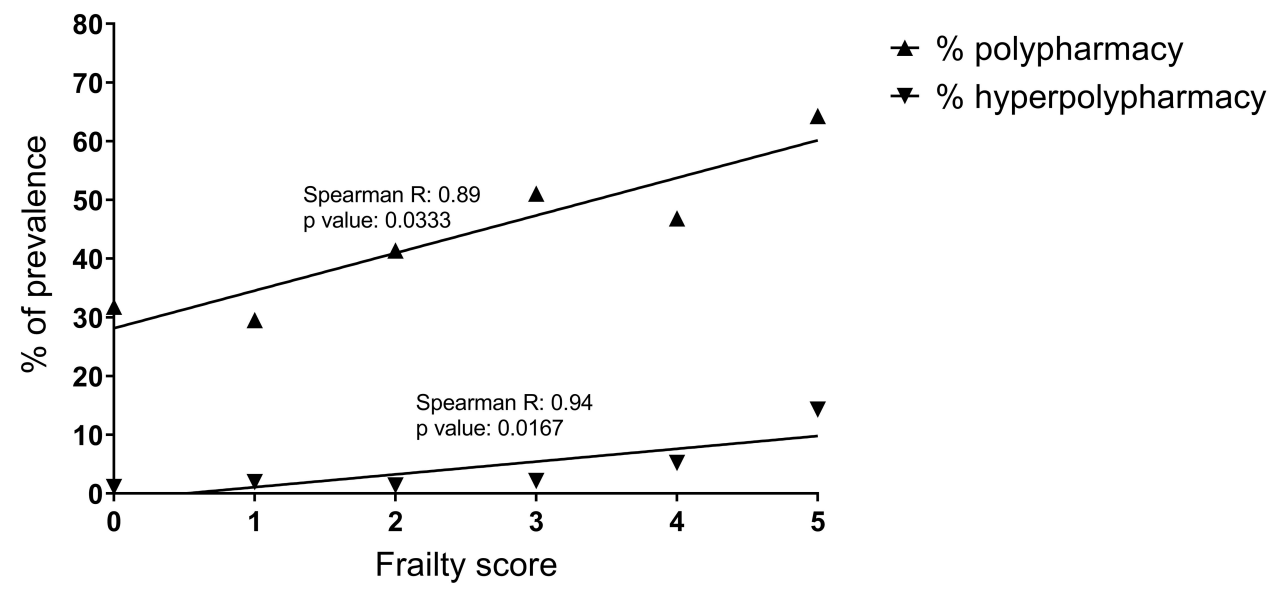

Figure I Correlation between frailty score and the prevalence of polypharmacy and non-polypharmacy state.

Note: The correlation analysis was performed by Spearman coefficient. 


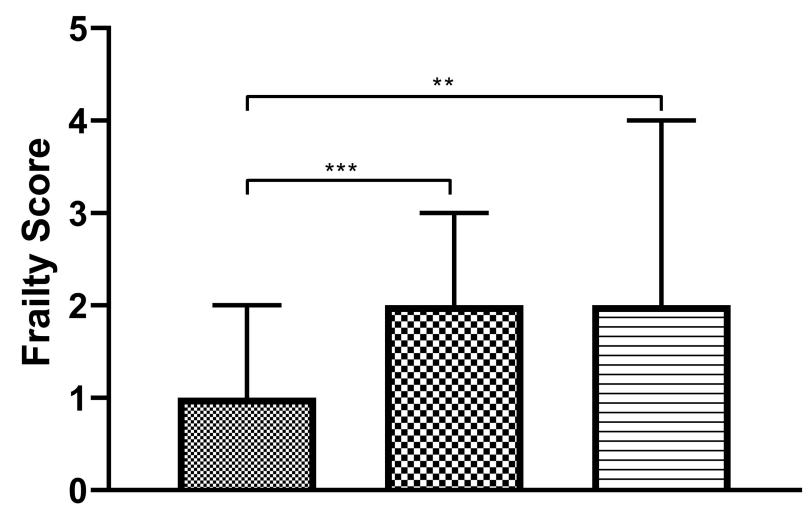

Non-polypharmacy
a Polypharmacy
․ Hyperpolypharmacy

Figure 2 Frailty score by polypharmacy status.

Notes: Kruskal-Wallis Test, one-way ANOVA. The bars represent the median and interquartile range. ${ }^{* * *} p<0.000 \mathrm{I},{ }^{* *} \mathrm{p}<0.00 \mathrm{I}$ (Dunn's Test).

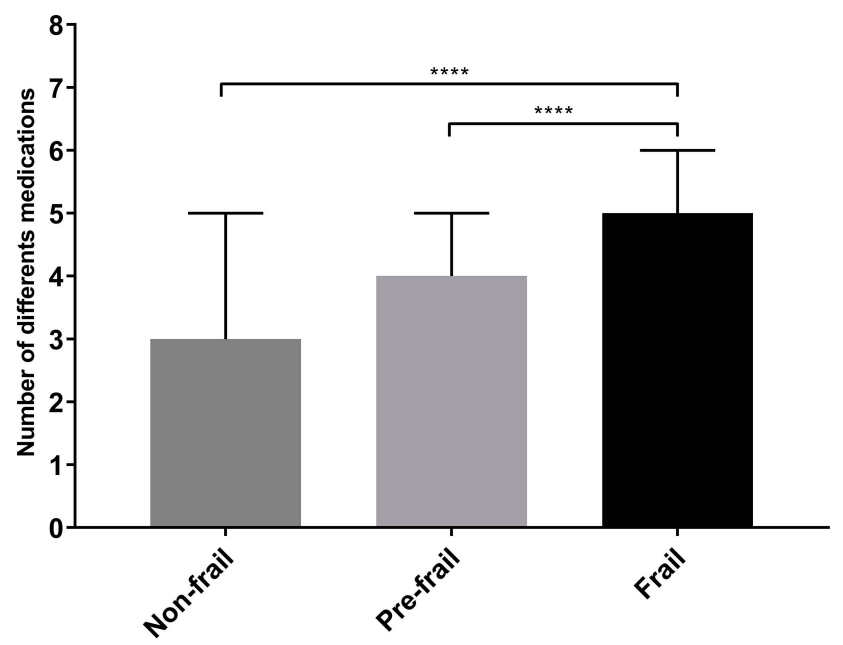

Figure 3 Number of daily medications consumed according to the state of frailty. Notes: ${ }^{* * * *} p<0.0001$ (Kruskal-Wallis Test, one-way ANOVA). The bars represent the median and interquartile range.

As seen in Figure 3, there were significant differences between the frail, pre-frail and non-frail groups ( $p$ $<0.0001$ ), showing a greater consumption of daily medications in the frail one. This result makes sense and accords with prior results. Other studies state the same, like the one reported in 2012 by Gnjidic et al. ${ }^{35}$

Our results show and confirm the strong union between the presence of polypharmacy and frailty, as observed in other large cohorts of older adults. ${ }^{14}$ An important point to consider for subsequent studies is also to evaluate the consumption of self-medicated drugs, since the geriatric population has a high prevalence of this characteristic, and is a key factor in the analysis of polypharmacy. ${ }^{36}$ Worldwide, exist an approximate prevalence of $40 \%$ of polypharmacy. ${ }^{37}$ The latest reports in Chile show that $36 \%$ of older adults have a polypharmacy status. ${ }^{38}$ However, in the National Health Survey of the year 2010, on average, a Chilean older adult would consume 4.27 drugs daily. ${ }^{38,39}$ Our results show an overall prevalence of polypharmacy of $39.59 \%$, being slightly higher compared to the previous report. This high global prevalence, and highlighted in Chile, increases the risk of dependency in older adults (because of the relationship with the state of frailty), being so a factor that should be considered in the integration of a preventive approach to dependency on older adults, especially in the Chilean population. ${ }^{40}$

\section{Conclusion}

In summary, we can conclude that frail condition is an important risk factor for polypharmacy, independently from age, residential area and education years. The presence of frailty and chronic medical conditions as nutritional risk, obesity, hypertension, diabetes, and respiratory diseases are significant risk factors for polypharmacy in the cohort studied. Likewise, the presence of polypharmacy was associated with the presence of frailty, observing the bidirectional relationship between both phenomena. These results coincide with what was observed in other cohorts of older adults; however, further research is needed to confirm the possible benefits of reducing polypharmacy in the development, reversion or delay of frailty. Frailty status evaluation in older adults could be an important alternative for polypharmacy prevention.

\section{Ethics}

This study was conducted in accordance with the Declaration of Helsinki. Written informed consents were obtained from every participant of this study.

\section{Disclosure}

The authors report no conflicts of interest in this work. 


\section{References}

1. Nations United. World population prospects: the 2010 revision; 2011. Available from: https://www.un.org/en/development/desa/publica tions/world-population-prospects-the-2010-revision.html.

2. Medical expenditure panel survey; 2006. Available from: https:// www.meps.ahrq.gov/mepsweb/.

3. Rollason V, Vogt N. Reduction of polypharmacy in the elderly: a systematic review of the role of the pharmacist. Drugs Aging. 2003;20(11):817-832. doi:10.2165/00002512-200320110-00003

4. Romero LME, Navarro J, Luengo C, et al. El Paciente Anciano: Demografía, Epidemiología y utilización de recursos. In: Gerontología S editor. Tratado de geriatría para residentes.

5. Ministerio de Salud de Chile. Encuesta Nacional de Salud; 2016-2017. Available from: https://www.minsal.cl/wp-content /uploads/2018/01/2-Resultados-ENS_MINSAL_31_01_2018.pdf.

6. Masnoon N, Shakib S, Kalisch-Ellett L, Caughey GE. What is polypharmacy? A systematic review of definitions. BMC Geriatr. 2017;17 (1):230. doi:10.1186/s12877-017-0621-2

7. Gnjidic D, Hilmer SN, Blyth FM, et al. Polypharmacy cutoff and outcomes: five or more medicines were used to identify community-dwelling older men at risk of different adverse outcomes. J Clin Epidemiol. 2012;65(9):989-995. doi:10.1016/j.jclinepi.2012.02.018

8. Saum KU, Schottker B, Meid AD, et al. Is polypharmacy associated with frailty in older people? Results from the ESTHER cohort study. $J$ Am Geriatr Soc. 2017;65(2):e27-e32. doi:10.1111/jgs.14718

9. Xue QL. The frailty syndrome: definition and natural history. Clin Geriatr Med. 2011;27(1):1-15. doi:10.1016/j.cger.2010.08.009

10. Garcia-Garcia FJ, Carcaillon L, Fernandez-Tresguerres J, et al. A new operational definition of frailty: the frailty trait scale. J Am Med Dir Assoc. 2014;15(5):371e7- e13. doi:10.1016/j.jamda.2014.01.004

11. Fried LP, Tangen CM, Walston J, et al. Frailty in older adults evidence for a phenotype. J Gerontol a Biol Sci Med Sci. 2001;56 (3):M146-M57.

12. Rosted E, Schultz M, Sanders S. Frailty and polypharmacy in elderly patients are associated with a high readmission risk. Dan Med J. 2016;63(9):A5274.

13. Bonaga B, Sanchez-Jurado PM, Martinez-Reig M, et al. Frailty, polypharmacy, and health outcomes in older adults: the frailty and dependence in albacete study. J Am Med Dir Assoc. 2018;19 (1):46-52. doi:10.1016/j.jamda.2017.07.008

14. Herr M, Robine JM, Pinot J, Arvieu JJ, Ankri J. Polypharmacy and frailty: prevalence, relationship, and impact on mortality in a French sample of 2350 old people. Pharmacoepidemiol Drug Saf. 2015;24 (6):637-646. doi:10.1002/pds.3772

15. Comans TA, Peel NM, Hubbard RE, Mulligan AD, Gray LC, Scuffham PA. The increase in healthcare costs associated with frailty in older people discharged to a post-acute transition care program. Age Ageing. 2016;45(2):317-320. doi:10.1093/ageing/afv196

16. Ensrud KE, Kats AM, Schousboe JT, et al. Frailty phenotype and healthcare costs and utilization in older women. $J$ Am Geriatr Soc. 2018;66(7):1276-1283. doi:10.1111/jgs.15381

17. Liotta G, Gilardi F, Orlando S, et al. Cost of hospital care for the older adults according to their level of frailty. A cohort study in the Lazio region, Italy. PLoS One. 2019;14(6):e0217829. doi:10.1371/ journal.pone. 0217829

18. Palomo I, Giacaman RA, Leon S, et al. Analysis of the characteristics and components for the frailty syndrome in older adults from central Chile. The PIEI-ES study. Arch Gerontol Geriatr. 2019;80:70-75. doi:10.1016/j.archger.2018.10.004

19. Instituto Nacional de Estadísticas. Resultados CENSO; 2017. Available from: http://resultados.censo2017.cl/.

20. Fuentes JLG, Jirón M. Estudio de prevalencia de uso de medicamentos potencialmente inapropiados en adultos mayores atendidos en atención primaria en salud. 2009.
21. Carvalho MFC, Romano-Lieber NS, Bergsten-Mendes G, et al. Polifarmácia entre idosos do Município de São Paulo - Estudo SABE. Rev Bras Epidemiol. 2012;15(4):817-827. doi:10.1590/ S1415-790X2012000400013

22. Palmer K, Villani ER, Vetrano DL, et al. Association of polypharmacy and hyperpolypharmacy with frailty states: a systematic review and meta-analysis. Eur Geriatr Med. 2019;10(1):9-36. doi:10.1007/ s41999-018-0124-5

23. Guralnik JM, Simonsick EM, Ferrucci L, et al. A short physical performance battery assessing lower extremity function: association with self-reported disability and prediction of mortality and nursing home admission. J Gerontol. 1994;49(2):M85-94. doi:10.1093/geronj/49.2. M85

24. Arroyo P, Lera L, Sanchez H, Bunout D, Santos JL, Albala C. Anthropometry, body composition and functional limitations in the elderly. Rev Med Chil. 2007;135(7):846-854. doi:10.4067/s003498872007000700004

25. Albala C, Lera L, Sanchez H, et al. Frequency of frailty and its association with cognitive status and survival in older Chileans. Clin Interv Aging. 2017;12:995-1001. doi:10.2147/CIA.S136906

26. Garcia-Garcia FJ, Gutierrez Avila G, Alfaro-Acha A, et al. The prevalence of frailty syndrome in an older population from Spain. The Toledo study for healthy aging. J Nutr Health Aging. 2011;15 (10):852-856. doi:10.1007/s12603-011-0075-8

27. Santos-Eggimann B, Cuenoud P, Spagnoli J, Junod J. Prevalence of frailty in middle-aged and older community-dwelling Europeans living in 10 countries. J Gerontol a Biol Sci Med Sci. 2009;64 (6):675-681. doi:10.1093/gerona/glp012

28. Nascimento R, Álvares J, Guerra Junior AA, et al. Polypharmacy: a challenge for the primary health care of the Brazilian unified health system. Rev Saude Publica. 2017;51:19s.

29. Cano-Guitierrez C, Samper-Ternent R, Cabrera J, Rosselli D. Uso de medicamentos en adultos mayores de Bogotá, Colombia. Rev Peru Med Exp Salud Publica. 2016;33(3):419-424. doi:10.17843/ rpmesp.2016.333.2292

30. Landi F, Dell'Aquila G, Collamati A, et al. Anticholinergic drug use and negative outcomes among the frail elderly population living in a nursing home. J Am Med Dir Assoc. 2014;15(11):825-829. doi:10.1016/j.jamda.2014.08.002

31. Moulis F, Moulis G, Balardy L, et al. Exposure to atropinic drugs and frailty status. J Am Med Dir Assoc. 2015;16(3):253-257. doi:10.10 16/j.jamda.2014.11.017

32. Wang R, Chen L, Fan L, et al. Incidence and effects of polypharmacy on clinical outcome among patients aged 80+: a five-year follow-up study. PLoS One. 2015;10(11):e0142123. doi:10.1371/journal. pone. 0142123

33. Aubert CE, Streit S, Da Costa BR, et al. Polypharmacy and specific comorbidities in university primary care settings. Eur J Intern Med. 2016;35:35-42. doi:10.1016/j.ejim.2016.05.022

34. Gutierrez-Valencia $\mathrm{M}$, Izquierdo $\mathrm{M}$, Cesari $\mathrm{M}$, Casas-Herrero $\mathrm{A}$, Inzitari M, Martinez-Velilla N. The relationship between frailty and polypharmacy in older people: a systematic review. $\mathrm{Br} J$ Clin Pharmacol. 2018;84(7):1432-1444. doi:10.1111/bcp.13590

35. Gnjidic D, Hilmer SN, Blyth FM, et al. High-risk prescribing and incidence of frailty among older community-dwelling men. Clin Pharmacol Ther. 2012;91(3):521-528. doi:10.1038/clpt.2011.258

36. Ruiz ME. Risks of self-medication practices. Curr Drug Saf. 2010;5 (4):315-323. doi:10.2174/157488610792245966

37. Morin L, Johnell K, Laroche M-L, Fastbom J, Wastesson JW. The epidemiology of polypharmacy in older adults: register-based prospective cohort study. Clin Epidemiol. 2018;10:289-298. doi:10.21 47/CLEP.S153458

38. Salech F, Daniel Palma QF, Pablo Garrido QF. Epidemiología del uso de Medicamentos en el adulto mayor. Rev Méd Clín Las Condes. 2016;27(5):660-670. doi:10.1016/j.rmclc.2016.09.011 
39. Homero GE. Polifarmacia y morbilidad en adultos mayores. Rev Méd Clín Las Condes. 2012;23(1):31-35. doi:10.1016/S0716-8640(12) 70270-5
40. Rolland Y, Morley JE. Frailty and polypharmacy. $J$ Nutr Health Aging. 2016;20(6):645-646. doi:10.1007/s12603-015-0510-3

\section{Publish your work in this journal}

Clinical Interventions in Aging is an international, peer-reviewed journal focusing on evidence-based reports on the value or lack thereof of treatments intended to prevent or delay the onset of maladaptive correlates of aging in human beings. This journal is indexed on PubMed Central, MedLine, CAS, Scopus and the Elsevier
Bibliographic databases. The manuscript management system is completely online and includes a very quick and fair peer-review system, which is all easy to use. Visit http://www.dovepress.com/ testimonials.php to read real quotes from published authors. 